\title{
The Possibilities of Washing Machine Parts' Modal Parameters Estimation
}

\author{
Martin Hagara, Pavol Lengvarský, Róbert Huňady \\ Faculty of Mechanical Engineering, Technical University of Kosice. Letna 9, SK042 00 Kosice. Slovakia. E-mail: \\ martin.hagara@tuke.sk, pavol.lengvarsky@tuke.sk, robert.hunady@tuke.sk
}

The paper describes the possibility to streamline the process of modal parameters estimation performed on the washing machine heater. As the shape of the mentioned part does not allow to capture its response to excitation using conventional gages of acceleration, Polytec PDV-100 vibrometer based on laser Doppler vibrometry method was used. Such a non-contact device captures the response in a form of velocity only at one point in one direction. For that reason, the process of modal parameters estimation can be relatively timeconsuming, especially in case if the vibration of the analyzed structure occurs in more than one direction. The authors speed up the process of response capturing using full-field high-speed digital image correlation system Q-450 Dantec Dynamics allowing investigation of the displacements in three mutually perpendicular directions. Its adaption for experimental modal analysis was ensured by developing an additional software called DICMAN 3D. As the output from the stereo camera system is in a form of 3D displacements in time, DICMAN 3D allows evaluating a single or multi-reference measurement using several algorithms. As the operational temperatures of the heater change due to the chosen wash cycle, the authors used numerical modeling to analyze the influence of the temperature on the heater natural frequencies shift.

Keywords: Washing Machine Heater, Experimental Modal Analysis, Digital Image Correlation, Laser Doppler Vibrometry, Finite Element Analysis

\section{Introduction}

Modal analysis as a tool for determination of socalled modal parameters plays an important role in the process of design of nearly all buildings, technical devices or machines (referred to systems), as knowledge of natural frequencies leads to the important information when the mechanical resonance can occur [1], [2], [3]. Mechanical resonance has a negative effect on most of the moving/vibrating systems because the magnitudes of vibration are increasing, leading to a higher level of noise or even destroying the system. In general, there are two types of modal analyses, i.e. an experimental and operational modal analysis. The experimental one is based on the calculation of the ratio between the output and input values in the frequency domain. To the input values, the data obtained from exciters (e.g. impact hammer allowing transient excitation or electro-dynamic shaker allowing harmonics excitation) can be assigned. The data acquired from the vibration sensors (e.g. vibrometers, accelerometers, scanning devices, etc.) belong to the outputs. On the other hand, the operational modal analysis is based on the analysis of the structure output, whereby the loading is ensured by a particular structure operation. Operational modal analysis is mostly used in technical practice where the structures are situated in in-situ conditions.

To know the natural frequencies of the washing machine (or just its parts) is a necessary part of the constructors' work, because of the smaller level of washing machine vibration, the smaller level of its noise and thus higher level of comfort for the users. Experimental and numerical modal analysis of the washing machine cabinet was realized by Rong and Yingya [4], whereby the maximal difference of ca. $6 \%$ was achieved between the numerical results based on finite element analysis and experimental results obtained using conventional transducer of acceleration and modal hammer. Kim and Lawrence [5] in 2005 considered with a noise problem, occurring by one of the wash cycles of a new type of washing machine at $100 \mathrm{~Hz}$ frequency, which corresponds to the frequency of its motor. For a reason that the noise and vibration of the motor could be magnified by resonances in other parts of the washing machine, they recognized to shift the frequency of the motor lower. Modifying the numerical model of motor, they achieved the reduction of the washing machine sound pressure level by $3 \mathrm{dBA}$ for the problem cycle. Modal parameters of washing machine pulley were analyzed by Schrötter et al. [6] in 2014. By the free support of the pulley, the authors achieved a good correspondence to the results obtained numerically. The influence of the higher wash cycle temperatures on the same part of the washing machine was numerically analyzed in 2015 by Lengvarský et al. [7]. As the pulley is quite robust, the noticed changes in its natural frequencies 
are negligible.

The heater serving for the heating of the water is located near to the washing machine motor and drum and its inordinate vibration can lead to the failure of washing machine important parts. This is the main reason why the authors decided to analyze its dynamics behavior.

\section{Experimental modal analysis of the heater performed by laser Doppler vibrometry method}

At first, the experimental modal analysis of the 1950W/230V AEG 1325064234 heater (see Fig. 1) was realized using Brüel\&Kjær PULSE system specialized for vibration analysis. To ensure the same support of the heater as in the washing machine a robust frame was constructed, to which the heater was attached using a screw bolt.

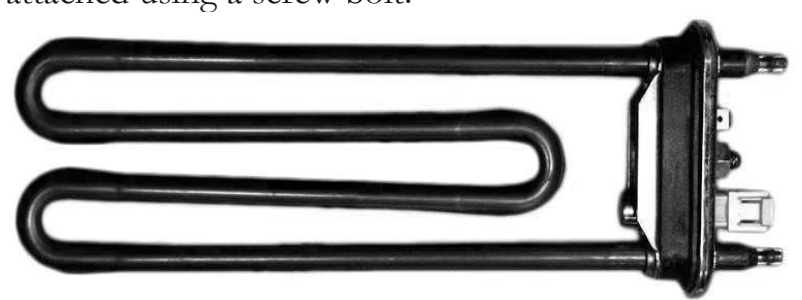

Fig. 1 Analysed 1950W/230V AEG 1325064234 washing machine heater

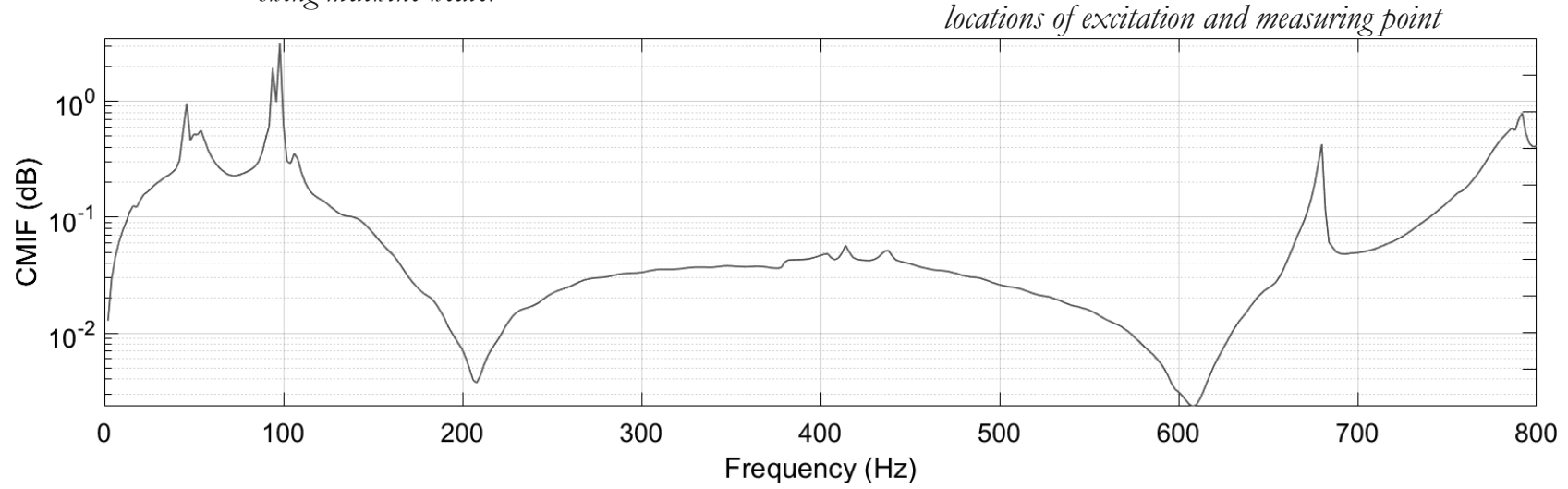

Fig. 3 CMIF plot of the heater (Pulse Reflex ${ }^{\circledR}$ )

The Rational Fraction Polynomial-Z (RFP-Z) and Polyreference time (PT) method were used to estimate the modal parameters of the heater. The software Pulse Reflex ${ }^{\circledR}$ identified seven modes of the heater.
To achieve the results with sufficient quality, it is required to create a proper model, which provides a sufficient number of measuring points and fulfills the condition that the measurement is as effective as possible. For that reason, the authors decided to realize a simplified line model of the heater spiral. The number of locations, in which the heater was excited by modal hammer Brüel\&Kjær 8206 with aluminum tip, was 36 (Fig. 2). The responses in a form of velocity were captured at 1 measuring point (DOF) by the vibrometer Polytec PDV-100 based on laser Doppler principle. The acquisition time for each measurement was $0.5 \mathrm{~s}$. The averaging of the results was performed after every three impacts of the hammer to the particular location. The measurement was evaluated in the frequency range from $0 \mathrm{~Hz}$ up to $800 \mathrm{~Hz}$ in the software Pulse Reflex®. Fig. 3 shows the CMIF plot, in which several dominant peaks can be identified.

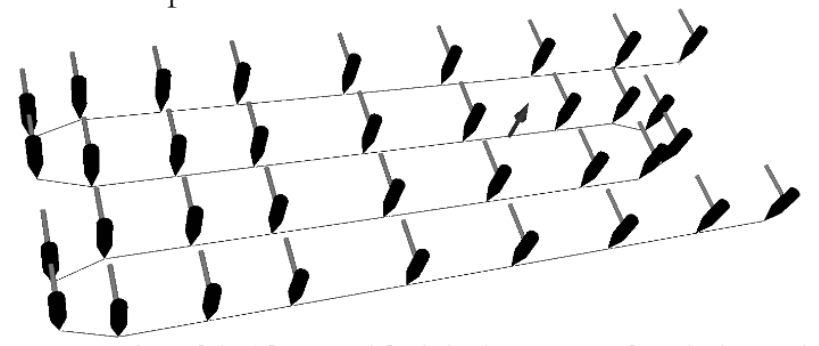

Fig. 2 Simplified line model of the heater spiral with depicted locations of excitation and measuring point

Their parameters obtained from the stability diagrams are listed in Table 1. Moreover, The Auto-MAC matrix is present in Table 2. Six of the mode shapes obtained by Pulse Reflex ${ }^{\circledR}$ are shown in Fig. 11.

Tab. 1 Modal parameters of the heater obtained by Pulse Reflex ${ }^{\circledR}$

\begin{tabular}{|c|c|c|c|}
\hline \multirow{2}{*}{ Mode } & Method & Frequency (Hz) & Damping ratio (\%) \\
\hline 1 & RFP-Z & 54.04 & 1.78 \\
\hline 2 & RFP-Z & 95.82 & 1.29 \\
\hline 3 & PT & 106.21 & 2.39 \\
\hline 4 & PT & 408.45 & 1.73 \\
\hline 5 & PT & 437.46 & 0.79 \\
\hline 6 & RFP-Z & 679.08 & 0.71 \\
\hline 7 & RFP-Z & 789.76 & 0.08 \\
\hline
\end{tabular}


Tab. 2 Auto-MAC matrix obtained by PULSE Reflex ${ }^{\circledR}$

\begin{tabular}{|c|c|c|c|c|c|c|c|}
\hline Frequency $(\mathrm{Hz})$ & 54.04 & 95.82 & 106.21 & 408.45 & 437.46 & 679.08 & 789.76 \\
\hline 54.04 & 1 & 0.049 & 0.038 & 0.696 & 0.770 & 0.084 & 0.025 \\
\hline 95.82 & 0.049 & 1 & 0.319 & 0.204 & 0.176 & 0.029 & 0.006 \\
\hline 106.21 & 0.038 & 0.319 & 1 & 0.119 & 0.090 & 0.007 & 0.088 \\
\hline 408.45 & 0.696 & 0.204 & 0.119 & 1 & 0.883 & 0.038 & 0.002 \\
\hline 437.36 & 0.770 & 0.176 & 0.090 & 0.883 & 1 & 0.045 & 0.001 \\
\hline 679.08 & 0.084 & 0.029 & 0.007 & 0.038 & 0.045 & 1 & 0.016 \\
\hline 789.76 & 0.025 & 0.006 & 0.088 & 0.002 & 0.001 & 0.016 & 1 \\
\hline
\end{tabular}

\section{Experimental modal analysis of the heater performed by high-speed digital image correlation method}

As the procedure mentioned above is very timeconsuming and leads only to the finding of dominant vibration responses in the normal (out-of-plane) direction corresponding to the direction of the arrow depicted in Fig. 2, the authors decided to use their unique method combining excitation by modal hammer and capturing responses by high-speed 3D digital image correlation system [8]. Digital image correlation is an optical method allowing non-contact full-field

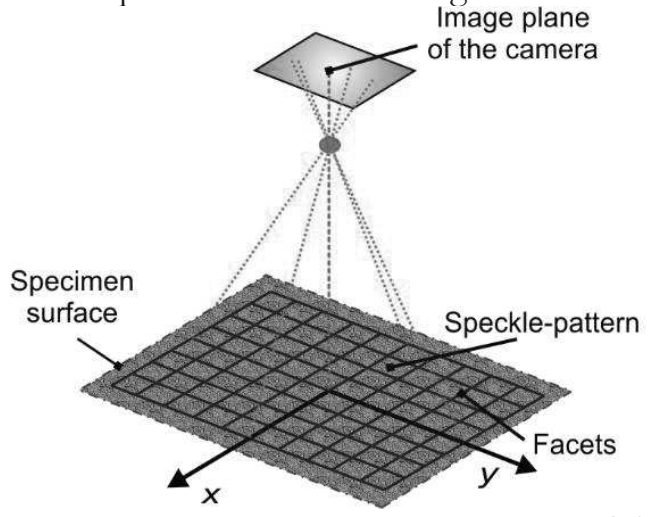

displacement and strain analysis. It is based on the comparison (called correlation) of the small picture elements known as facets (subsets) with a common squared shape with a size from $10 \times 10$ px up to $50 \times$ $50 \mathrm{px}$ depending on the size and position of the analysed object. To ensure that each facet is unique, the random black and white speckle pattern is created on the analysed object surface. In general, the measurement can be performed using a single- or multi-camera system (Fig. 4). The resulting data in the form of displacements and strains are obtained in the centre of each facet.

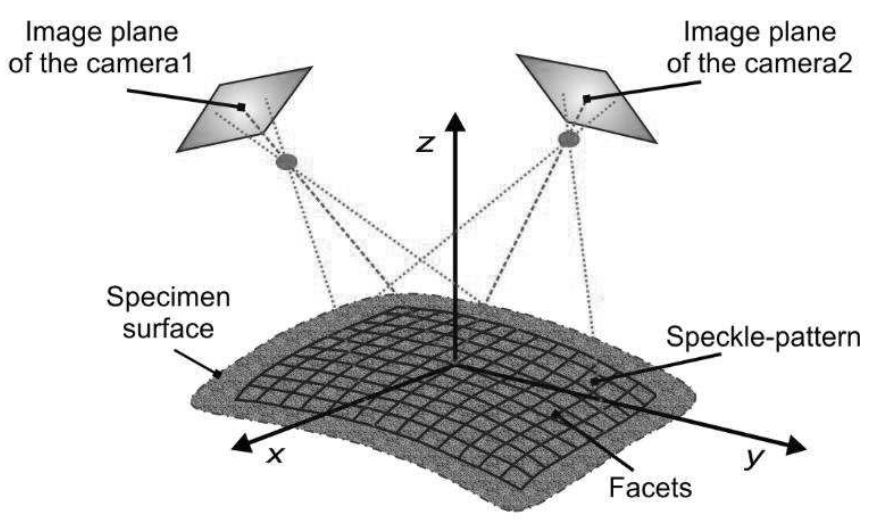

Fig. 4 Scheme of single- (left) and stereo-camera system

The correlation system containing one digital camera can be used for the analysis of in-plane displacements performed on the flat objects. The correlation system created by more than one camera can be used for the analysis of in-plane as well as out-of-plane displacements of the objects with curved contour.

To obtain information about the transformation coordinates of the analysed object points, Dantec Dynamics correlation devices use an algorithm based on a pseudo-affine transformation. If the transformation parameters of possible displacement, elongation, shear and distortion of the facet $\mathrm{a}_{0}-\mathrm{a}_{7}$ are considered (Fig. 5), according to the algorithm mentioned above the transformation coordinates $\left(x^{*}, y^{*}\right)$ can be calculated as follows:

$$
\begin{aligned}
& x^{*}\left(a_{0}, a_{1}, a_{2}, a_{3}, x, y\right)=a_{0}+a_{1} x+a_{2} y+a_{3} x y[p x] \\
& y^{*}\left(a_{4}, a_{5}, a_{6}, a_{7}, x, y\right)=a_{4}+a_{5} x+a_{6} y+a_{7} x y[p x]
\end{aligned}
$$

Correlation parameters are determined by finding the minimum of the correlation function, dependent on twelve-components deformation vector $\mathbf{p}$ (individual displacements and strains), given by the relation:

$$
C(\mathbf{p})=\sum_{x, y} l(x, y)-\left(g_{0}+g_{1}{ }^{*}\left(x^{*}(x, y), y^{*}(x, y)\right)\right)[-],(2)
$$

where:

$g_{0}, g_{1} \ldots$ brightness parameters $[-]$, $I(x, y) \ldots$ grey value of the pixels with coordinates $x, y$ in the reference image $[-]$, $I^{*}\left(x^{*}, y^{*}\right) \ldots$ grey value of the pixels with coordinates $x^{*}, y^{*}$ in the distorted image $[-]$.

The only condition for the reconstruction of the object contour is that the analysed area has to be seen 
in the field of view of the corresponding cameras' pair. To reconstruct the bodies with more spatially complicated contour, the correlation systems (mainly the low-speed systems due to the costs and hardware demands) with a higher number of cameras, e.g. three-, four- or even eight-cameras digital image correlation systems or so-called mirror-assisted pseudo-stereo systems have been developed [9-13].

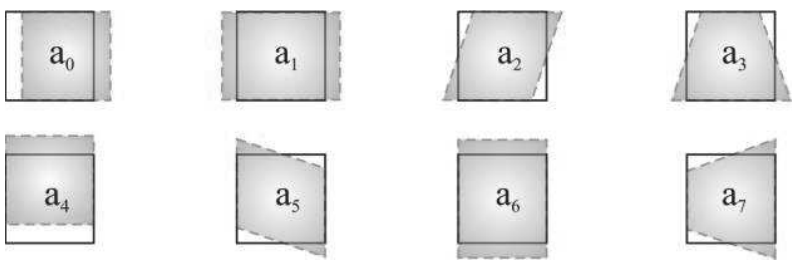

Fig. 5 Transformation parameters used in the algorithm based on a pseudo-affine transformation

The authors have adapted the high-speed digital image correlation system Q-450 Dantec Dynamics for the use in the modal analysis, which is conditioned by the acquisition of an excitation signal from an impact hammer. For that purpose, the AD/DA converter, which is the part of the correlation system, is used. The only part of the measuring chain added to the correlation system was the CCLD amplifier, which the impact hammer is directly connected to. The amplified signal is fed to one of the analog inputs as well as to the Trigger-In input ensuring the measurement is started automatically after the impact of the hammer (see the scheme of Q-450 configuration depicted in Fig. 6). The excitation signal is synchronized with the acquisition of the images [8]. Such a set-up correlation system is not more expensive then the conventional methods (e.g. PULSE system) and the measurement with the subsequent modal parameters estimation can be realised by any person having some experience with correlation systems and some knowledge from the experimental modal analysis.

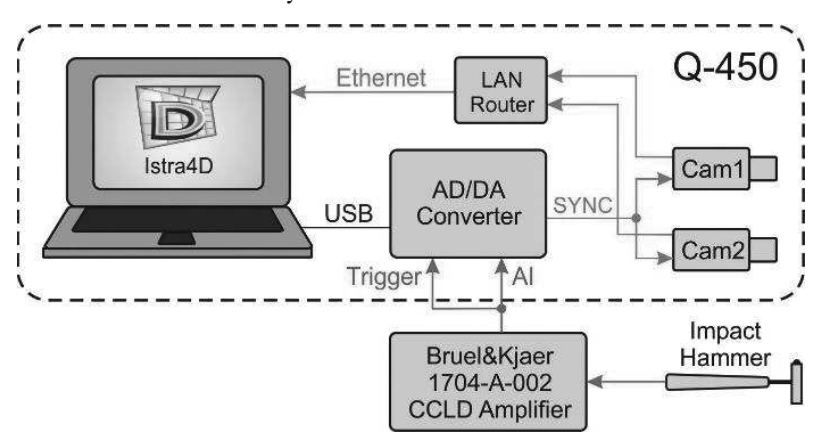

Fig. 6 The scheme for the experimental modal analysis realisation using Q-450 Dantec Dynamics [8]

DICMAN 3D is a unique open-source application developed to post-process the data obtained from a measurement performed by a high-speed stereo-camera digital image correlation system Q-450 Dantec Dynamics. Its graphical user interface was created by the authors in Matlab allowing easy data transfer from Istra 4D (Q-450's correlation software), which the data exported from has the hierarchical data format (HDF5). The actual version is built on a new concept that efficiently uses computer memory and significantly saves on computational time. It can be used for the evaluation of a single-reference as well as multireference measurement in three-dimensional space. Normally, the number of facets reconstructed on the analysed object surface is several thousands that leads to several thousands of Frequency Response Functions (FRF). For that reason, the response model is graphically expressed by Normal Mode Indicator Function (NMIF), Complex Mode Indicator Function (CMIF), or averaged FRF. Modal parameters are determined in the frequency domain using Rational Fraction Polynomial (RFP) method and Frequency Domain Polynomial (FDP) method. The mode shape validation is performed through Modal Assurance Criterion (MAC) or Modal Phase Collinearity (MPC). The application contains also the advanced estimation module, where Enhanced Frequency Response Function (EFRF) allows fast and more accurate automatic estimation of natural frequencies and damping ratios, especially for measurements with a high spatial resolution. The working diagram of the software DICMAN 3D can be seen in Fig. 7 [8].

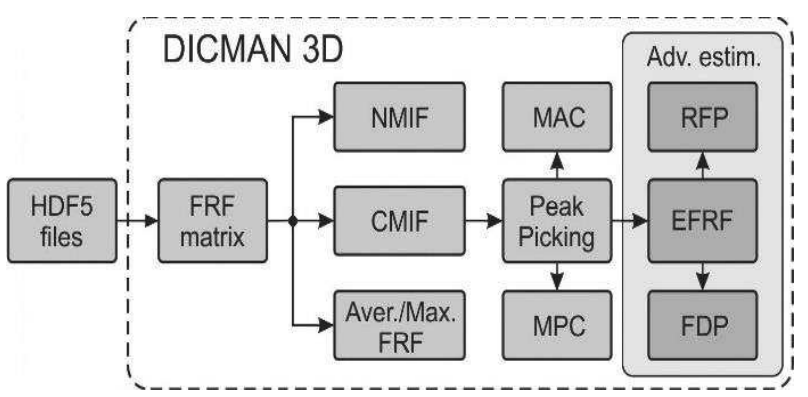

Fig. 7 Working diagram of DICMAN $3 D[8]$

The main advantages of this procedure are:

- just one impact of the hammer needed for the realization of the measurement,

- simultaneous contactless collection of the response data in three mutually perpendicular directions from more DOFs.

Compared to the conventional techniques using accelerometers or measuring devices based e.g. on the interference principle, the main drawbacks of DIC are:

- smaller sensitivity to lower vibration,

- the common stereo-camera system does not allow to reconstruct highly spatially complicated bodies,

- complicated/impossible set-up of cameras in case of the investigated body with difficult visible/invisible location. 

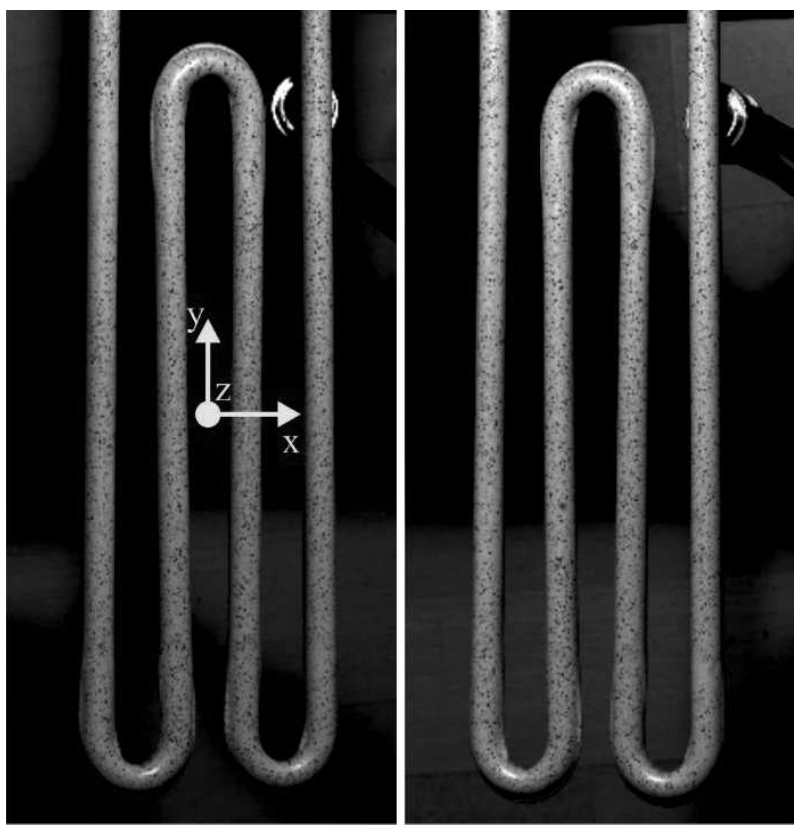

Fig. 8 Reference images captured by high-speed digital image correlation system Q-450 Dantec Dynamics
By the realisation of the experiment, the cameras of the high-speed digital image correlation system Q450 Dantec Dynamics acquired images at $2000 \mathrm{fps}$ with a resolution of $400 \times 800 \mathrm{px}$ (see Fig. 8).

The acquisition time was set to 0.5 s, i.e. 1000 images were captured totally. The calibration target with $15 \mathrm{~mm}$ square pattern (Al-15-BMB_9x9) was used to obtain the calibration parameters (focal length, principal point coordinates, tangential and radial distortion, mutual position and rotation of the cameras) of the camera system. The facet size was set to $10 \mathrm{px}$ with an overlap of 3 px between the facets. Therefore, the specimen contour was approximated by a virtual grid with 1611 nodal points (DOFs) at which the vibration responses in a form of $3 \mathrm{D}$ displacements were measured. The data acquired from the measurement was imported into DICMAN 3D for modal parameter estimation.

The CMIF plot obtained by DICMAN 3D in three perpendicular directions (Z-direction is a normal one), from which ten modes of the heater spiral were found, can be seen in Fig. 9 .

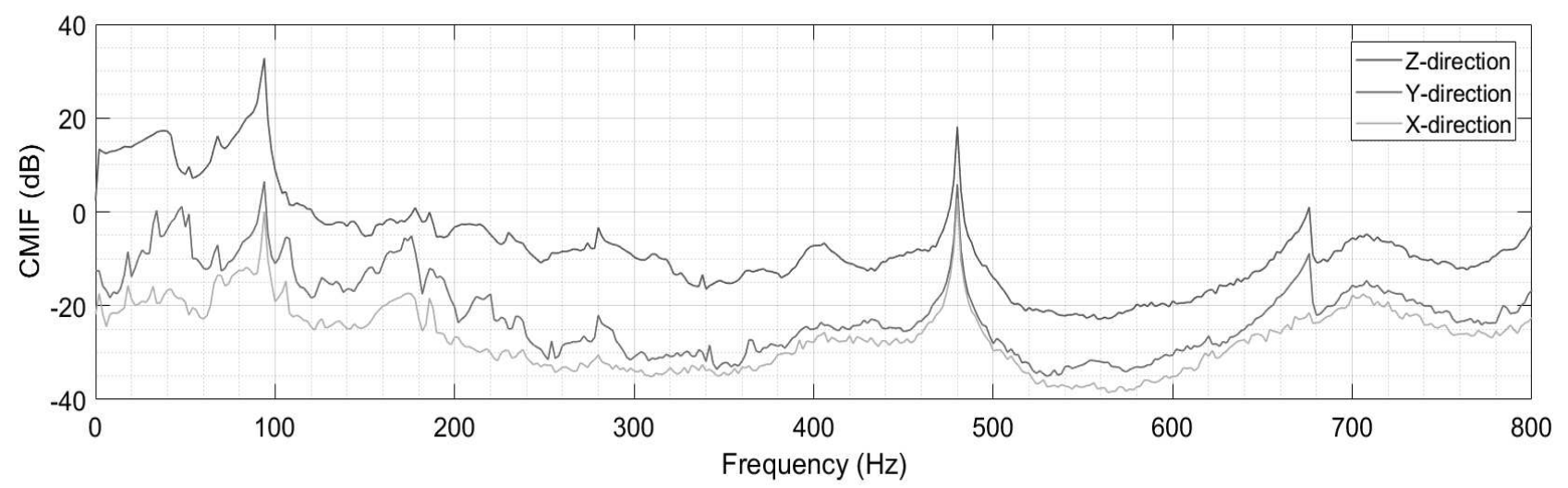

Fig. 9CMIF plot of the heater (DICMAN 3D)

The Rational Fraction Polynomial-Z (RFP-Z) method was used to estimate the modal parameters of the heater. The parameters of vibration obtained by DICMAN 3D stability diagrams are listed in Table 3.

Tab. 3 Modal parameters of the heater obtained by DICMAN 3D

\begin{tabular}{|c|c|c|c|}
\hline Mode & Method & Frequency $(\mathrm{Hz})$ & Damping ratio (\%) \\
\hline 1 & RFP-Z & 52.37 & 1.08 \\
\hline 2 & RFP-Z & 56.04 & 0.31 \\
\hline 3 & RFP-Z & 94.65 & 0.91 \\
\hline 4 & RFP-Z & 106.37 & 0.53 \\
\hline 5 & RFP-Z & 108.89 & 3.23 \\
\hline 6 & RFP-Z & 184.29 & 0.72 \\
\hline 7 & RFP-Z & 404.16 & 2.34 \\
\hline 8 & RFP-Z & 432.24 & 0.43 \\
\hline 9 & RFP-Z & 619.12 & 0.24 \\
\hline 10 & RFP-Z & 674.06 & 0.45 \\
\hline
\end{tabular}

Moreover, the Auto-MAC matrix is present in Table 4. All the mode shapes obtained by DICMAN 3D are shown in Fig. 11. 
Tab. 4 Auto-MAC matrix obtained by DICMAN 3D

\begin{tabular}{|c|c|c|c|c|c|c|c|c|c|c|}
\hline Frequency $(\mathrm{Hz})$ & 52.37 & 56.04 & 94.65 & 106.37 & 108.89 & 184.29 & 404.16 & 432.24 & 619.12 & 674.06 \\
\hline 52.37 & 1 & 0.532 & 0.106 & 0.063 & 0.143 & 0.009 & 0.122 & 0.213 & 0.256 & 0.046 \\
\hline 56.04 & 0.532 & 1 & 0.227 & 0.082 & 0.466 & 0.019 & 0.536 & 0.684 & 0.485 & 0.159 \\
\hline 94.65 & 0.106 & 0.227 & 1 & 0.480 & 0.250 & 0.008 & 0.053 & 0.126 & 0.234 & 0.087 \\
\hline 106.37 & 0.063 & 0.082 & 0.480 & 1 & 0.393 & 0.014 & 0.031 & 0.089 & 0.049 & 0.078 \\
\hline 108.89 & 0.143 & 0.466 & 0.250 & 0.393 & 1 & 0.003 & 0.237 & 0.153 & 0.214 & 0.107 \\
\hline 184.29 & 0.009 & 0.019 & 0.008 & 0.014 & 0.003 & 1 & 0.008 & 0.084 & 0.043 & 0.088 \\
\hline 404.16 & 0.122 & 0.536 & 0.053 & 0.031 & 0.237 & 0.008 & 1 & 0.818 & 0.106 & 0.050 \\
\hline 432.24 & 0.213 & 0.684 & 0.126 & 0.089 & 0.153 & 0.084 & 0.818 & 1 & 0.215 & 0.026 \\
\hline 619.12 & 0.256 & 0.485 & 0.234 & 0.049 & 0.214 & 0.043 & 0.106 & 0.215 & 1 & 0.152 \\
\hline 674.06 & 0.046 & 0.159 & 0.087 & 0.078 & 0.107 & 0.088 & 0.050 & 0.026 & 0.152 & 1 \\
\hline
\end{tabular}

\section{Numerical modal analysis of the heater performed by Ansys Workbench}

Numerical modal analysis was performed in the simulation software Ansys Workbench 19.2 based on the finite element method. The simplified model of the heater (relieved of parts, which do not influence the results of analysis) depicted in Fig. 5 comprises several parts generated from Stainless steel 304 with the density of $8 \mathrm{e} 03 \mathrm{~kg} \cdot \mathrm{m}^{-3}$, Young's modulus of $1.95 \mathrm{e} 05$ $\mathrm{MPa}$ and Poisson's ratio of 0.29 , one part from Natural black rubber (depicted in Fig. 10 by green) with the density of $9.3 \mathrm{e} 02 \mathrm{~kg} \cdot \mathrm{m}^{-3}$, Young's modulus of $1 \mathrm{MPa}$, Poisson's ratio of 0.49 . The inner part of the heater spiral is filled by a magnesium-oxid with a defined density of $3.58 \mathrm{e} 03 \mathrm{~kg} \cdot \mathrm{m}^{-3}$, Young's modulus of $2.7 \mathrm{e} 02$ $\mathrm{MPa}$, Poisson's ratio of 0.35 .

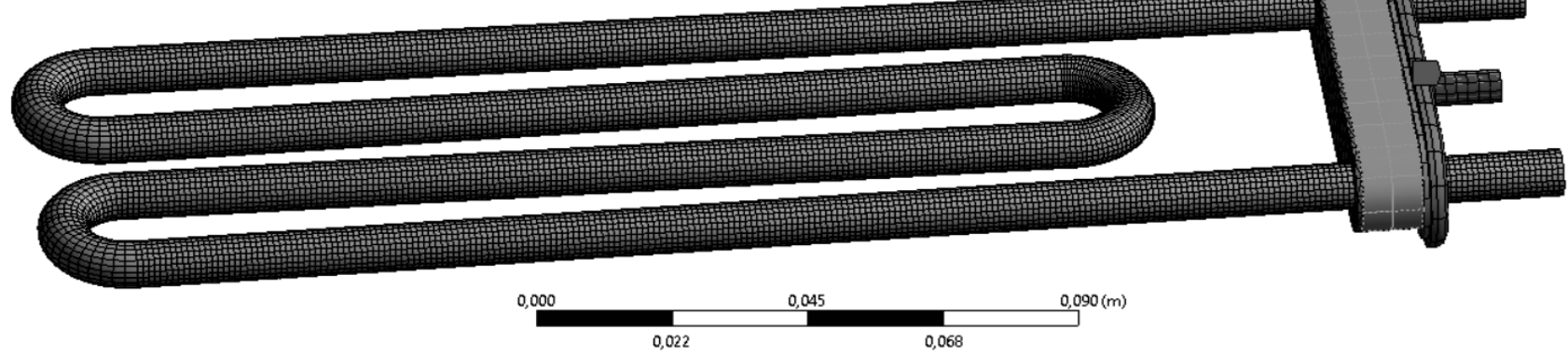

Fig. 10 Finite element model of the analysed heater

To ensure the real boundary conditions, the heater model was fixed in its middle part (depicted in Fig. 10 by blue). The finite element mesh consisting of hexahedrons has 26598 elements and 178319 nodes. The modal analysis was performed for the frequency range from $0 \mathrm{~Hz}$ up to $800 \mathrm{~Hz}$, whereby 13 modes of vibration were found. Twelve of them are depicted in Fig. 11.

Comparing the results from both experimental approaches (see Tab. 5), it can be stated that there are very small deviations obtained between the natural frequencies and thus the results can be considered as correct ones. These deviations can be caused by the different accuracy of the measurements dependent i.a. on the number of measuring locations. Comparing the results obtained experimentally with the numerical ones, the highest deviations (maximal value ca. $15 \%$ ) are obtained for the higher modes (7th and 8th one) outside the working frequencies of the heater. The 9th as well as the 10th mode of vibration is not found. The authors deduce that it is caused by the modes with small vibrations (cannot be captured by DIC due to its sensitivity) in the direction, which was not analysed by the vibrometer. In the frequency range from $0 \mathrm{~Hz}$ up to $150 \mathrm{~Hz}$, which can be considered as the working frequency range of the heater, the results are in good equality for all the approaches.

As all the analyses were performed by ca. $22{ }^{\circ} \mathrm{C}$ temperature, it was necessary to verify how the natural frequencies of the heater change, if the temperature increase to its operational mode, e.g. $40{ }^{\circ} \mathrm{C}, 60^{\circ} \mathrm{C}$ and $90^{\circ} \mathrm{C}$. Although both contactless experimental approaches allow investigating mentioned influence, the authors decided to use the numerical model, because of its good correspondence with experimental ones (especially in the operational frequency range of the washing machine). It can be stated that the operational temperature does not influence the natural frequencies of the heater significantly - the maximal shift was achieved at $90{ }^{\circ} \mathrm{C}$ temperature and reached ca. $5 \%$ decrease (see Tab. 6). The influence of the temperature is more significant in the higher frequency range, which is not relevant, because of the operational frequency range of the washing machine 


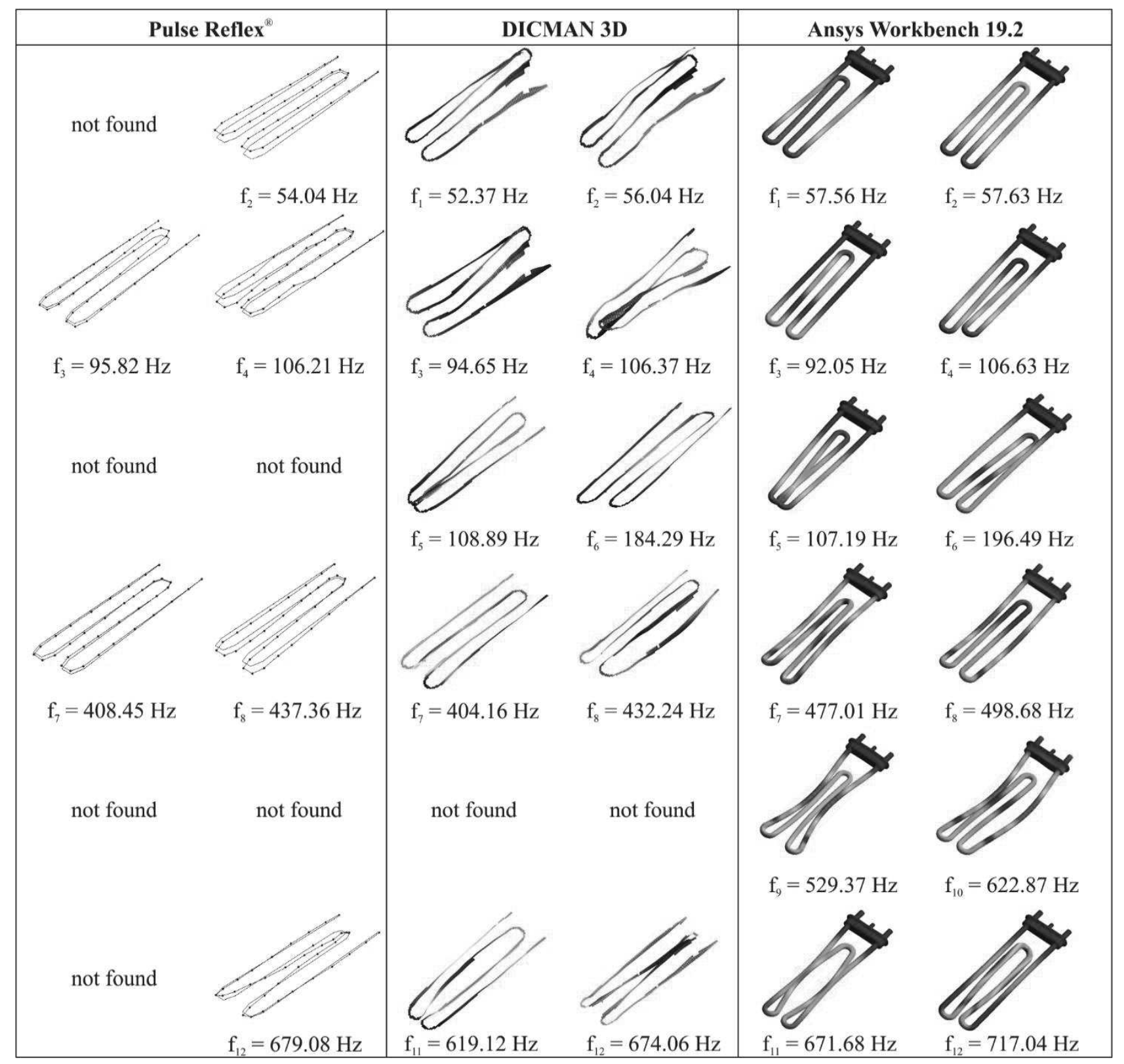

Fig. 11 The heater's modes of vibration obtained by used methods

Tab. 5 The qualitative comparison of the natural frequencies assessed by the used methods

\begin{tabular}{|c|c|c|c|}
\hline \multirow{2}{*}{ Mode } & \multicolumn{3}{|c|}{ Method } \\
\cline { 2 - 4 } & FEA (reference) & Pulse Reflex ${ }^{\circledR}$ & DICMAN 3D \\
\hline 1 & $57.56 \mathrm{~Hz}$ & not found & $52.37 \mathrm{~Hz}(-9.02 \%)$ \\
\hline 2 & $57.63 \mathrm{~Hz}$ & $54.04 \mathrm{~Hz}(-6.23 \%)$ & $56.04 \mathrm{~Hz}(-2.76 \%)$ \\
\hline 3 & $92.05 \mathrm{~Hz}$ & $95.82 \mathrm{~Hz}(+4.09 \%)$ & $94.65 \mathrm{~Hz}(+2.82 \%)$ \\
\hline 4 & $106.63 \mathrm{~Hz}$ & $106.21 \mathrm{~Hz}(-0.39 \%)$ & $106.37 \mathrm{~Hz}(-0.24 \%)$ \\
\hline 5 & $107.19 \mathrm{~Hz}$ & not found & $108.89 \mathrm{~Hz}(+1.59 \%)$ \\
\hline 6 & $196.49 \mathrm{~Hz}$ & not found & $184.29 \mathrm{~Hz}(-6.21 \%)$ \\
\hline 7 & $477.01 \mathrm{~Hz}$ & $408.45 \mathrm{~Hz}(-14.37 \%)$ & $404.16 \mathrm{~Hz}(-15.27 \%)$ \\
\hline 8 & $498.68 \mathrm{~Hz}$ & $437.36 \mathrm{~Hz}(-12.30 \%)$ & $432.24 \mathrm{~Hz}(-13.32 \%)$ \\
\hline 9 & $529.37 \mathrm{~Hz}$ & not found & not found \\
\hline 10 & $622.87 \mathrm{~Hz}$ & not found & not found \\
\hline 11 & $671.68 \mathrm{~Hz}$ & not found & $619.12 \mathrm{~Hz}(-7.83 \%)$ \\
\hline 12 & $717.04 \mathrm{~Hz}$ & $686.07 \mathrm{~Hz}(-4.32 \%)$ & $684.04 \mathrm{~Hz}(-4.60 \%)$ \\
\hline
\end{tabular}


Tab. 6 The influence of the temperature on the natural frequencies of the heater and their relative shift towards the reference values (obtained by $22^{\circ} \mathrm{C}$ )

\begin{tabular}{|c|c|c|c|c|}
\hline \multirow{2}{*}{ Mode } & \multicolumn{4}{|c|}{ Temperature } \\
\cline { 2 - 5 } & $22{ }^{\circ} \mathrm{C}($ ref. $)$ & $40{ }^{\circ} \mathrm{C}$ & $60{ }^{\circ} \mathrm{C}$ & $90{ }^{\circ} \mathrm{C}$ \\
\hline 1 & $57.56 \mathrm{~Hz}$ & $55.74 \mathrm{~Hz}(-3.16 \%)$ & $55.62 \mathrm{~Hz}(-3.37 \%)$ & $55.43 \mathrm{~Hz}(-3.70 \%)$ \\
\hline 2 & $57.63 \mathrm{~Hz}$ & $55.82 \mathrm{~Hz}(-3.14 \%)$ & $55.70 \mathrm{~Hz}(-3.35 \%)$ & $55.52 \mathrm{~Hz}(-3.66 \%)$ \\
\hline 3 & $92.05 \mathrm{~Hz}$ & $88.08 \mathrm{~Hz}(-4.31 \%)$ & $87.82 \mathrm{~Hz}(-4.60 \%)$ & $87.43 \mathrm{~Hz}(-5.02 \%)$ \\
\hline 4 & $106.63 \mathrm{~Hz}$ & $102.34 \mathrm{~Hz}(-4.02 \%)$ & $102.06 \mathrm{~Hz}(-4.29 \%)$ & $101.64 \mathrm{~Hz}(-4.68 \%)$ \\
\hline 5 & $107.19 \mathrm{~Hz}$ & $102.68 \mathrm{~Hz}(-4.21 \%)$ & $102.38 \mathrm{~Hz}(-4.49 \%)$ & $101.94 \mathrm{~Hz}(-4.90 \%)$ \\
\hline 6 & $196.49 \mathrm{~Hz}$ & $190.44 \mathrm{~Hz}(-3.08 \%)$ & $190.04 \mathrm{~Hz}(-3.28 \%)$ & $189.44 \mathrm{~Hz}(-3.59 \%)$ \\
\hline 7 & $477.01 \mathrm{~Hz}$ & $458.70 \mathrm{~Hz}(-3.84 \%)$ & $457.49 \mathrm{~Hz}(-4.09 \%)$ & $455.68 \mathrm{~Hz}(-4.47 \%)$ \\
\hline 8 & $498.68 \mathrm{~Hz}$ & $480.02 \mathrm{~Hz}(-3.74 \%)$ & $478.79 \mathrm{~Hz}(-3.99 \%)$ & $476.94 \mathrm{~Hz}(-4.36 \%)$ \\
\hline 9 & $529.37 \mathrm{~Hz}$ & $507.44 \mathrm{~Hz}(-4.14 \%)$ & $506.00 \mathrm{~Hz}(-4.41 \%)$ & $503.82 \mathrm{~Hz}(-4.83 \%)$ \\
\hline 10 & $622.87 \mathrm{~Hz}$ & $597.78 \mathrm{~Hz}(-4.03 \%)$ & $596.13 \mathrm{~Hz}(-4.29 \%)$ & $593.65 \mathrm{~Hz}(-4.69 \%)$ \\
\hline 11 & $671.68 \mathrm{~Hz}$ & $643.64 \mathrm{~Hz}(-4.17 \%)$ & $641.80 \mathrm{~Hz}(-4.45 \%)$ & $639.03 \mathrm{~Hz}(-4.86 \%)$ \\
\hline 12 & $717.04 \mathrm{~Hz}$ & $686.07 \mathrm{~Hz}(-4.32 \%)$ & $684.04 \mathrm{~Hz}(-4.60 \%)$ & $680.99 \mathrm{~Hz}(-5.03 \%)$ \\
\hline 13 & $768.14 \mathrm{~Hz}$ & $734.67 \mathrm{~Hz}(-4.36 \%)$ & $732.47 \mathrm{~Hz}(-4.64 \%)$ & $729.17 \mathrm{~Hz}(-5.07 \%)$ \\
\hline
\end{tabular}

\section{Conclusions}

The modal analysis of the washing machine heater is presented in the paper. For the verification of the modal parameters estimation, two contactless experimental approaches were used - specialized PULSE system with Polytec PDV-100 vibrometer and stereocamera high-speed DIC system. As the analysis of the vibration velocities was performed by the vibrometer only in normal (out-of-plane) direction, some important modes were not found. The mentioned modes could be found after repeating the measurement in the plane of the heater. As such procedure would be very time-consuming because the excitation of the heater in 36 locations had to be performed twice, the authors consider the DIC approach with unique software DICMAN 3D allowing determination of CMIF plot from displacements as more effective and precise because for the collecting of data in three mutually perpendicular directions simultaneously just after one impact of the impact hammer. The experimental results establish the numerical model as a correct one. The difference in the experimental and numerical results can relate to the ideal boundary conditions considered by numerical analysis. The results of the numerical analysis lead to the conclusion that the influence of the higher temperature on the natural frequency shift in the analyzed frequency range is not so significant (maximal decrease ca. $5 \%$ ). Due to three modes of vibration near to $100 \mathrm{~Hz}$, it would be necessary to know the operational frequency of the washing machine motor to decide whether the heater is designed correctly.

\section{Acknowledgement}

The paper is the result of the project implementation VEGA 1/0355/18.

\section{References}

[1] ŽMINDÁK, M., PELAGIĆ, Z., SOUKUP, J. (2015). Analysis of Fiber Orientation Influence to Dynamic Properties of Composite Structures. In: Manufacturing Technology, Vol. 15, No. 3, pp. 490 - 494. Univerzita J. E. Purkyně, Czech Republic.

[2] BULÍN, R., HAJŽMAN, M., POLACH, P., ŠIKA, Z., ZAVREL, J. (2017). Dynamical Analysis of a Cable Manipulator Using Multibody Approaches. In: Manufacturing Technology, Vol. 17, No. 2, pp. 151 - 157. Univerzita J. E. Purkyně, Czech Republic.

[3] KOVÁČIKOVÁ, P., VAVRO, J., VAVRO Jr., J., DUBEC, A. (2018). Microstructure Evaluation of Ductile Cast Iron and Numerical Modal Analysis. In: Manufacturing Technology, Vol. 18, No. 4, pp. 600 - 604. Univerzita J. E. Purkyně, Czech Republic.

[4] RONG, J., YINGYA, M. (2015). Test and simulation on modal analysis of drum washing machine cabinet. In: Proceedings of Seventh International Conference on Measuring Technology and Mechatronics Automation, (Central South University of Forest and Technology), pp. 1114 - 1117, China.

[5] KIM, R., LAWRENCE, R. (2005). Structureborne noise reduction in washing machines: Noise reduction by modal analysis. In: New Zealand Acoustics, Vol. 18, No. 4, pp. 18 - 21.

[6] SCHRÖTTER, M., HAGARA, M., LENGVARSKÝ, P. (2014). Experimental Modal Analysis of Washing Machine Pulley. 
In: Proceedings of 20th International Conference on Engineering Mechanics, (Institute of Thermomechanics AS CR), pp. 1 - 4. Czech Republic.

[7] LENGVARSKÝ, P., HAGARA, M., BOCKO, J. (2015). Analysis of the temperature influence on a shift of natural frequencies of washing machine pulley, In: American Journal of Mechanical Engineering, Vol. 3, No. 6, pp. 215 - 219. USA.

[8] HUŇADY, R., HAGARA, M. (2017). A new procedure of modal parameter estimation for high-speed digital image correlation. In: Mechanical Systems and Signal Processing, Vol. 93, pp. 66 - 79. England.

[9] MALESA, M., MALOWANY, K., PAWLICKI, J., KUJAWINSKA, M., SKRZYPCZAK, P., PIEKARCZUK, A., LUSA, T., ZAGORSKI, A. (2016). Non-destructive testing of industrial structures with the use of multi-camera Digital Image Correlation method. In: Engineering Failure Analysis, Vol. 69, pp. 122 - 134, England.
[10] YU, L., PAN, B. (2016). Single-camera stereodigital image correlation with a four-mirror adapter: optimized design and validation. In: Optics and Lasers in Engineering, Vol. 87, pp. 120 - 128, England.

[11] LI, J., DAN, X., XU, W., WANG, Y, YANG, G., YANG, L. (2017). 3D digital image correlation using single color camera pseudo-stereo system. In: Optics \& Laser Technology, Vol. 95, pp. 1 - 7, England.

[12] CHEN, B., PAN, B. (2019). Mirror-assisted panoramic-digital image correlation for full-surface 360-deg deformation measurement. In: Measurement, Vol. 132, pp. 350 - 358, England.

[13] CHEN, B., GENOVESE, K., PAN, B. (2020). In vivo panoramic human skin shape and deformation measurement using mirror-assisted multi-view digital image correlation. In: Journal of the Mechanical Behavior of Biomedical Materials, Vol. 110, pp. 1 - 10, Netherlands. 